\title{
POWER SYSTEM STABILITY IMPROVEMENT UNDER THREE PHASE FAULTS USING STATIC SYNCHRONOUS COMPENSATOR
}

\author{
Vikramarajan Jambulingam ${ }^{1}$ \\ ${ }^{1}$ Electrical and Electronics Engineering, VIT University
}

\begin{abstract}
In this research paper stability of power systems are analyzed by using a STATCOM. The STATCOM is a shunt connected facts devices. Mostly static compensator enhances the power system stability under three phase faults. The bus voltages are controlled using shunt type facts device. The control strategy is implemented by static synchronous compensator devices and it is found that system performance is enhanced under three phase faults. Due to three phase fault the problems arises in generator voltage, generator current, Infinite bus voltage, Infinite bus current and generator load angle of a power system are investigated in detail and resolved by designing and testing a test system using MATLAB/SIMULINK.
\end{abstract}

Keywords: STATCOM, FACTS, Transient stability

\section{INTRODUCTION}

The power generation and transmission is a complex process, requiring the working of many components of the power system in tandem to maximize the output. The shunt faults are the most regular type of faults taking place in the field [1]. Three phase faults caused due to falling tower, failure of equipment (or) even a line braking and touching the remaining phases can cause three phase faults [2]. The Flexible AC transmission system [FACTS] proposed in 1995.

The basic purpose of FACTS is installing the power electronics devices at the high voltage side of the power grid to make the complete system electronically controllable. Because of high power semiconductor devices and control technology FACTS devices plays a vital role in power systems.STATCOM is a second generation of the Flexible $\mathrm{AC}$ transmission system device. It comes under the category of fully controlled device based compensator. In improvement of transient stability using FACTS controller are analyzed [3].

Garg et al., reported about the voltage control and dynamic performances using static compensator [4]. Mathur et al., developed thyristor based Flexible AC transmission system controller for electrical transmission system [5].An improved STATCOM model for power flow analysis [6]. In this paper the control strategy is implemented using static synchronous compensator devices. It is found that, system stability is enhanced with three phase fault. Similarly five parameters are investigated in detail by designing and testing a test system using MATLAB/SIMULINK.
5. Generator load angle as $[\partial]$

\section{BLOCK DIAGRAM OF TEST SYSTEM}

The below test network is tested and parameters such as generator voltage, generator current, bus voltage, bus current and generator load angle performances are examined by connecting STATCOM devices.

Table.1 Test system specification

\begin{tabular}{|l|l|l|}
\hline \multicolumn{2}{|l|}{ Test system specification } \\
\hline Generator 1 & Generator 2 & STATCOM \\
\hline $10 \mathrm{KV}$ & $10 \mathrm{KV}$ & $10 \mathrm{KV}$ \\
\hline $110 \mathrm{MW}$ & $10 \mathrm{MVAR}$ & $10 \mathrm{MVAR}$ \\
\hline $300 \mathrm{RPM}$ & NA & NA \\
\hline
\end{tabular}

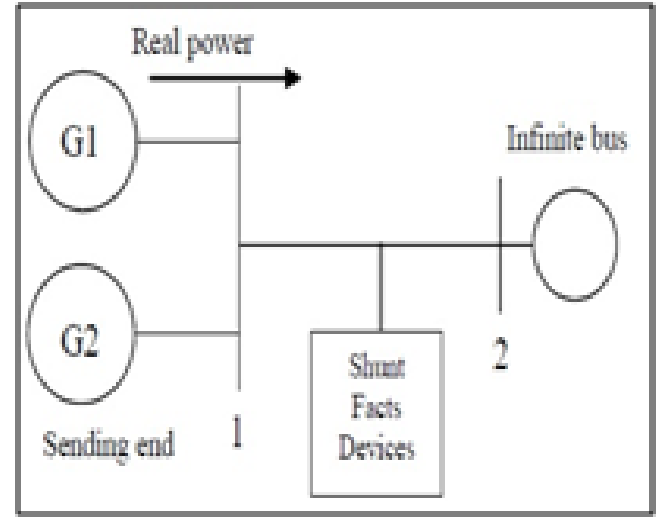

Fig-.1 Test system with shunt FACTS device

Five different Parameters are represented as follows:

1. Generator Voltage as $\left[\mathrm{V}_{\mathrm{g}}\right]$

2. Generator Current as $\left[\mathrm{I}_{\mathrm{g}}\right]$

3. Infinite Bus Voltage as $\left[\mathrm{V}_{\mathrm{b}}\right]$

4. Infinite Bus Current as $\left[\mathrm{I}_{\mathrm{b}}\right]$ 
3. DESIGN AND WORKING OPERATION OF STATIC COMPENSATOR

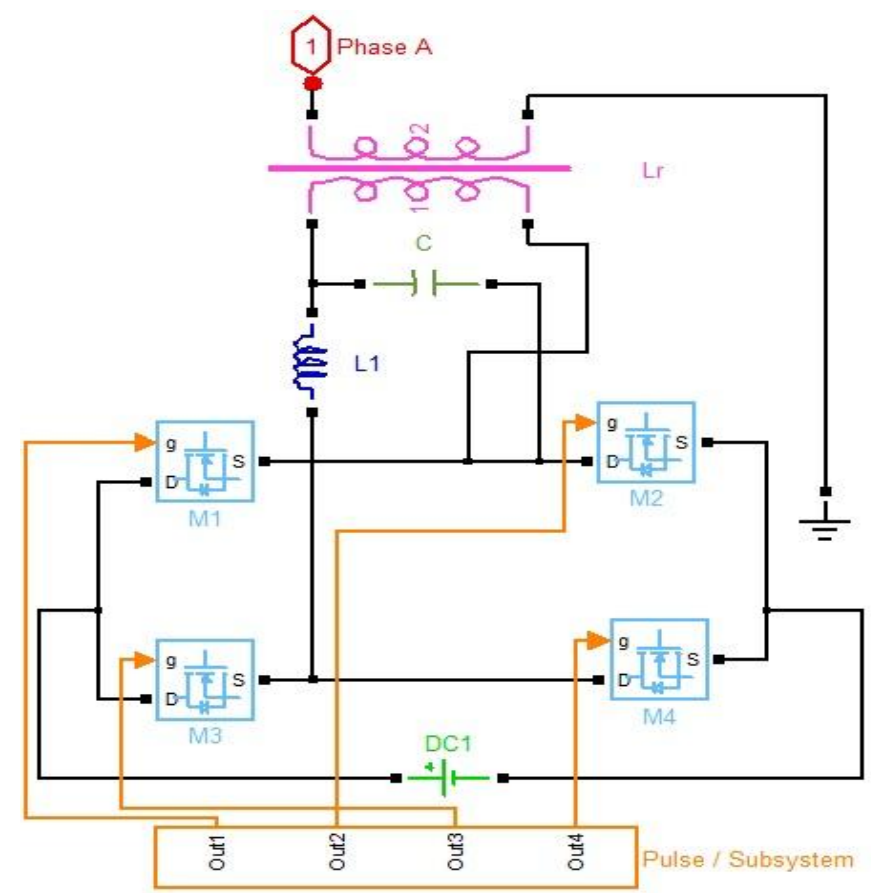

Fig.2 Design of Static compensator

The static compensator primarily consists of a VSC [voltage source converter], shunt connected transformer and DC capacitor [7]. At the same time the voltage source converter is linked to a utility bus through magnetic coupling.

Even though it acts like a static part of the rotating synchronous devices, the absence of moving parts makes it to work faster than the older dynamic compensators.

The Phase [A] design of STATCOM [static synchronous compensator] is shown in figure.2. The static compensator is a controlled reactive power source. This provides the desired reactive power generation and absorbtion entirely by means of electronic processing of the voltage and current waveforms in a voltage source converter.

Stage1: The amplitude of three phase output voltage varied therefore reactive power exchange can be controlled.

Stage 2: The amplitude of output voltage is increased more than bus voltage, so current starts flowing from voltage source converter to AC system through reactance and generates capacitive reactive power.

Stage 3: The amplitude of output voltage is decreased less than bus voltage, so current starts flowing from AC system to voltage source converter through reactance and absorbs inductive reactive power.

Stage 4: The output voltage with AC system voltage is equal, so reactive power exchange becomes zero and static compensator goes to floating state.

\subsection{Procedure to Build Up a Test System}

Step 1: Design a Test system and create three phase faults near infinite bus as shown in figure 4 .

Step 2: Measure the generator voltage, generator current, Bus voltage, Bus current and generator load angle.

Step 3: Design a Static compensator (Figure.2) and connect to the test system as shown in figure.5.

Step 4: Measure the generator voltage, generator current, Bus voltage, Bus current and generator load angle.

Step 5: Compare both the result of test system as shown in table. 2 


\section{SIMULATION MODEL OF TEST SYSTEM}

\subsection{Test System with Three Phase Fault}

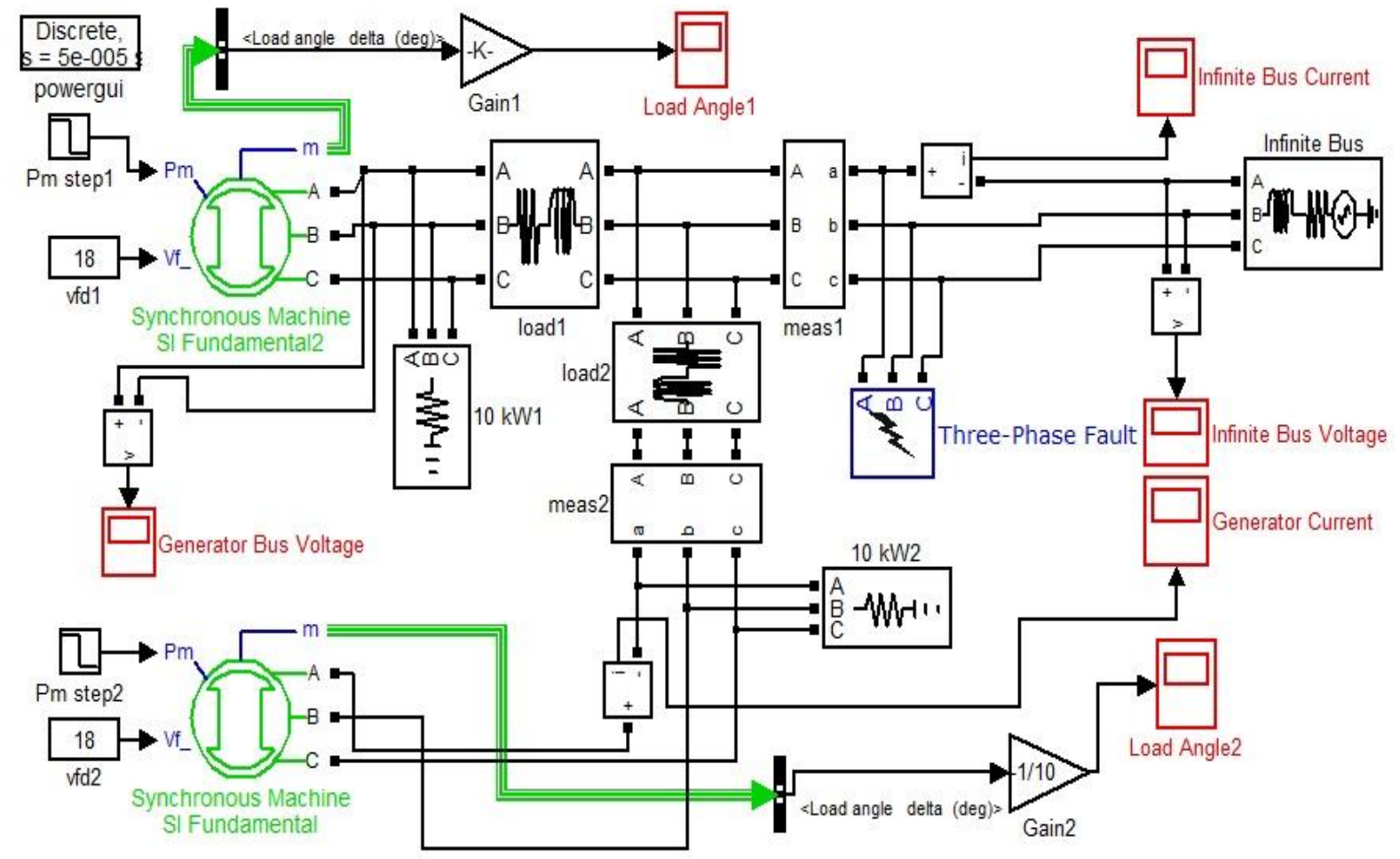

Fig.3 Test system with three phase fault

\subsection{Test System with Static Synchronous Compensator}

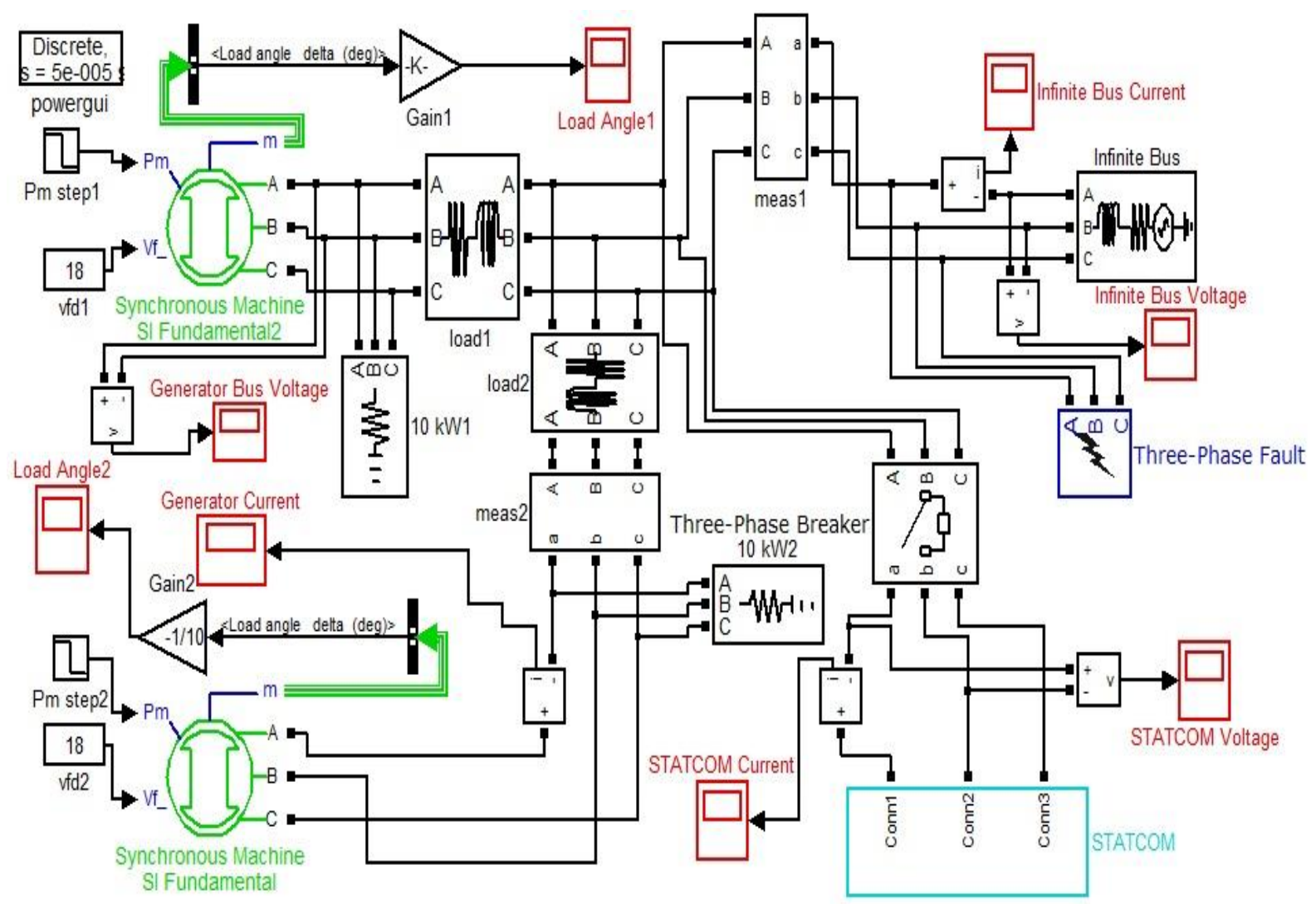

Fig 4 Test system with static synchronous compensator 


\section{SIMULATION RESULTS}
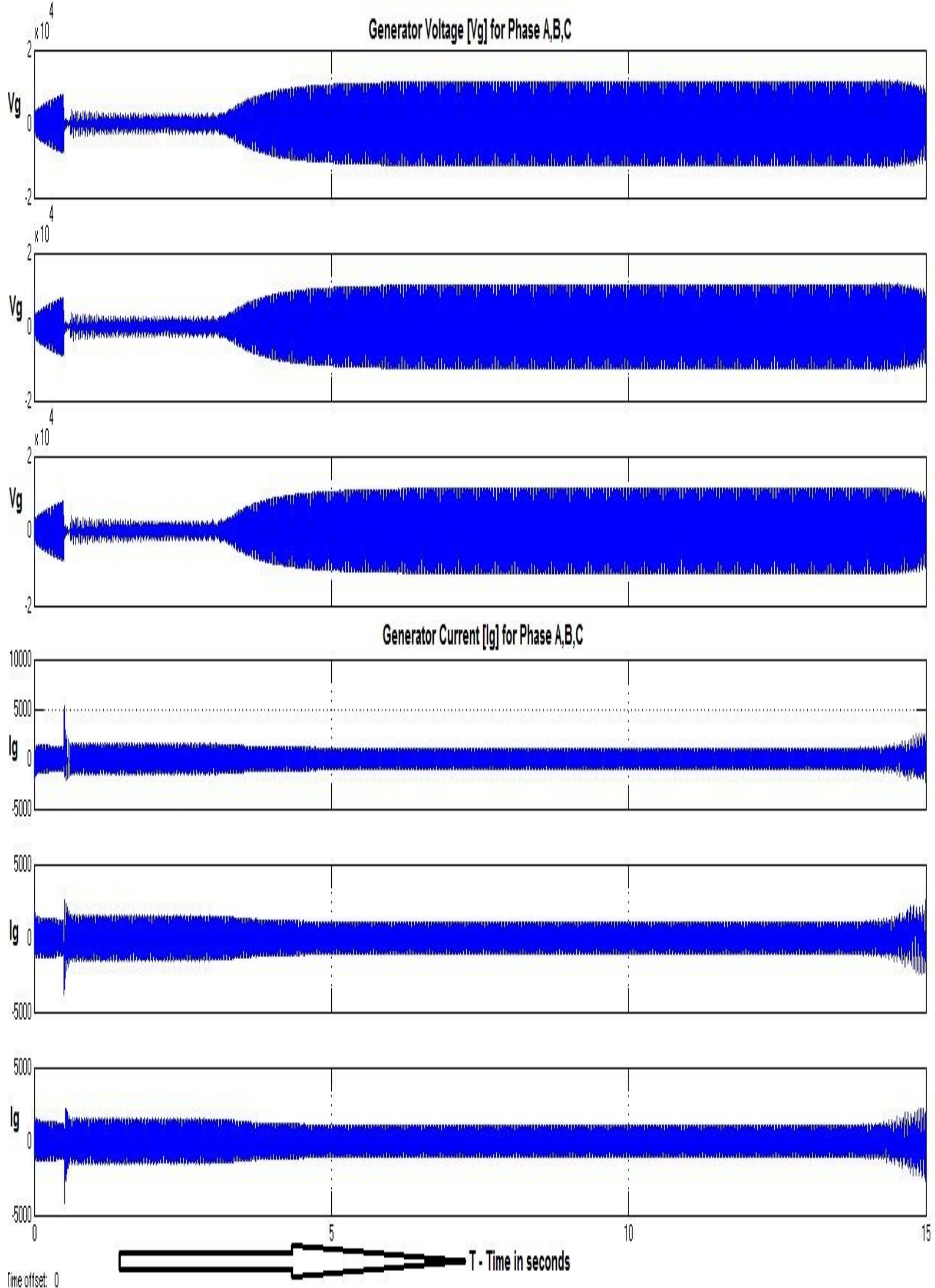

Fig.5 Represents generator voltage and current of test system with three phase faults 

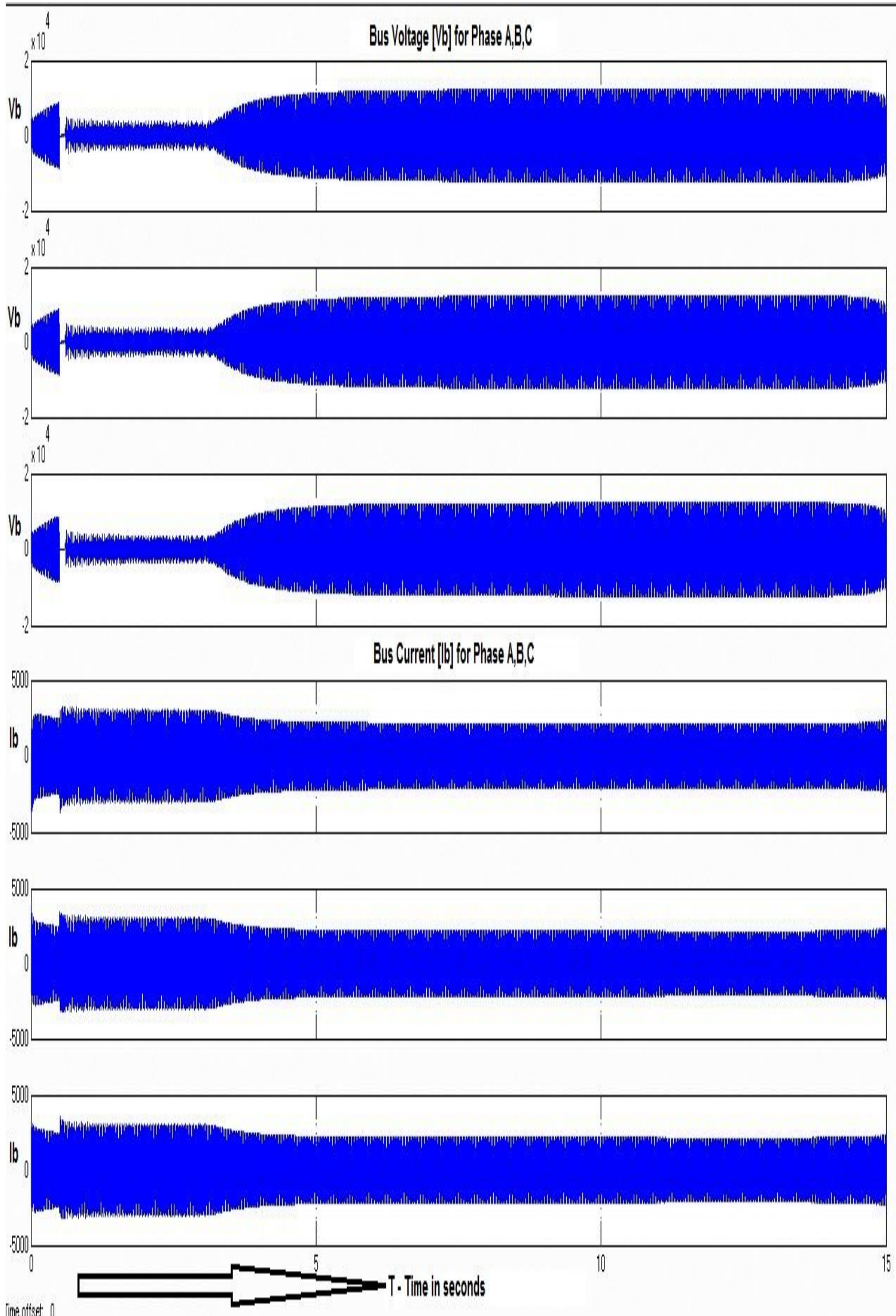

Fig 6 Represents bus voltage and current of test system with three phase faults 

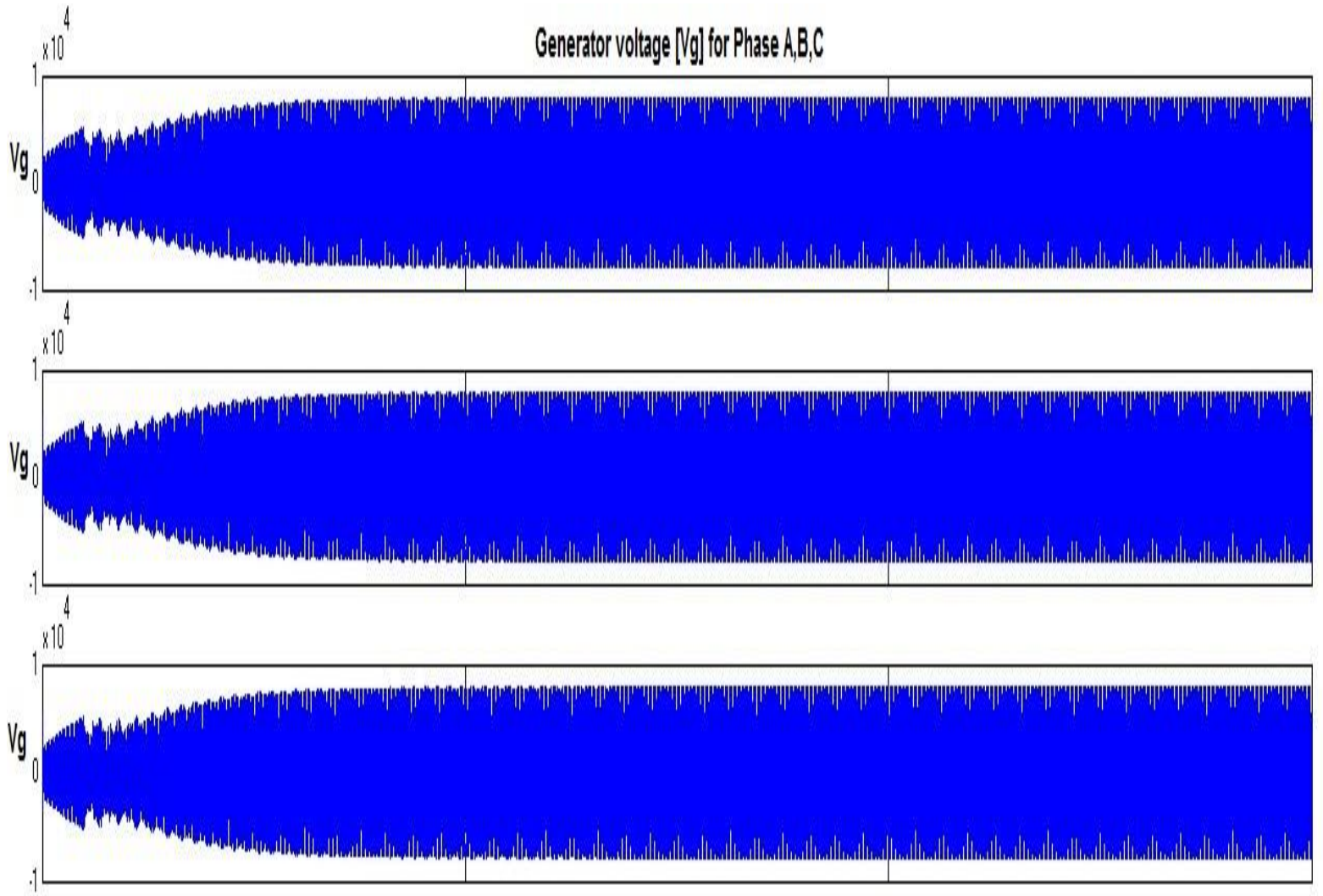

Generator Current"log for Phase A,B,C
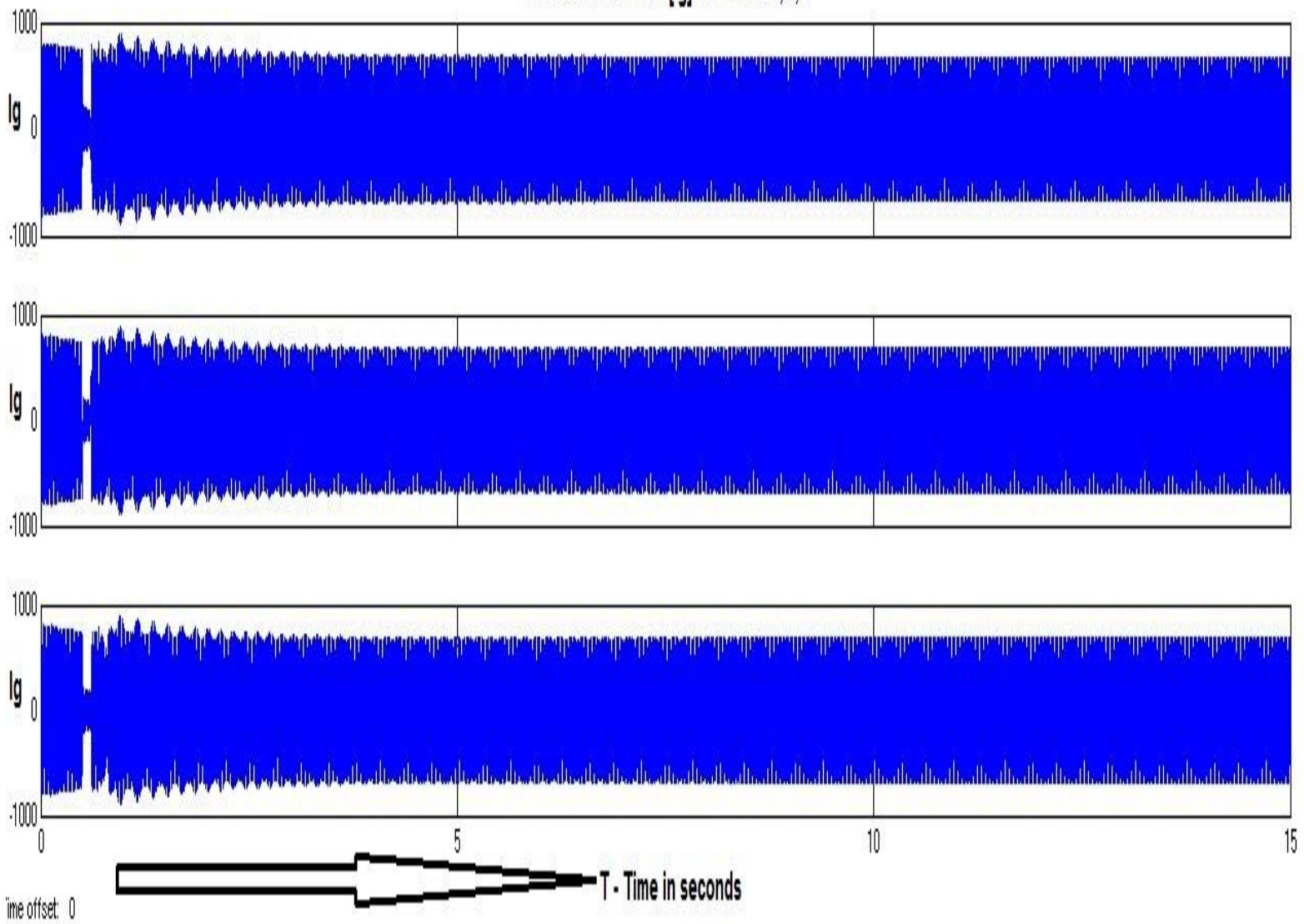

Fig.7. Represents generator voltage and current of test system with STATCOM 

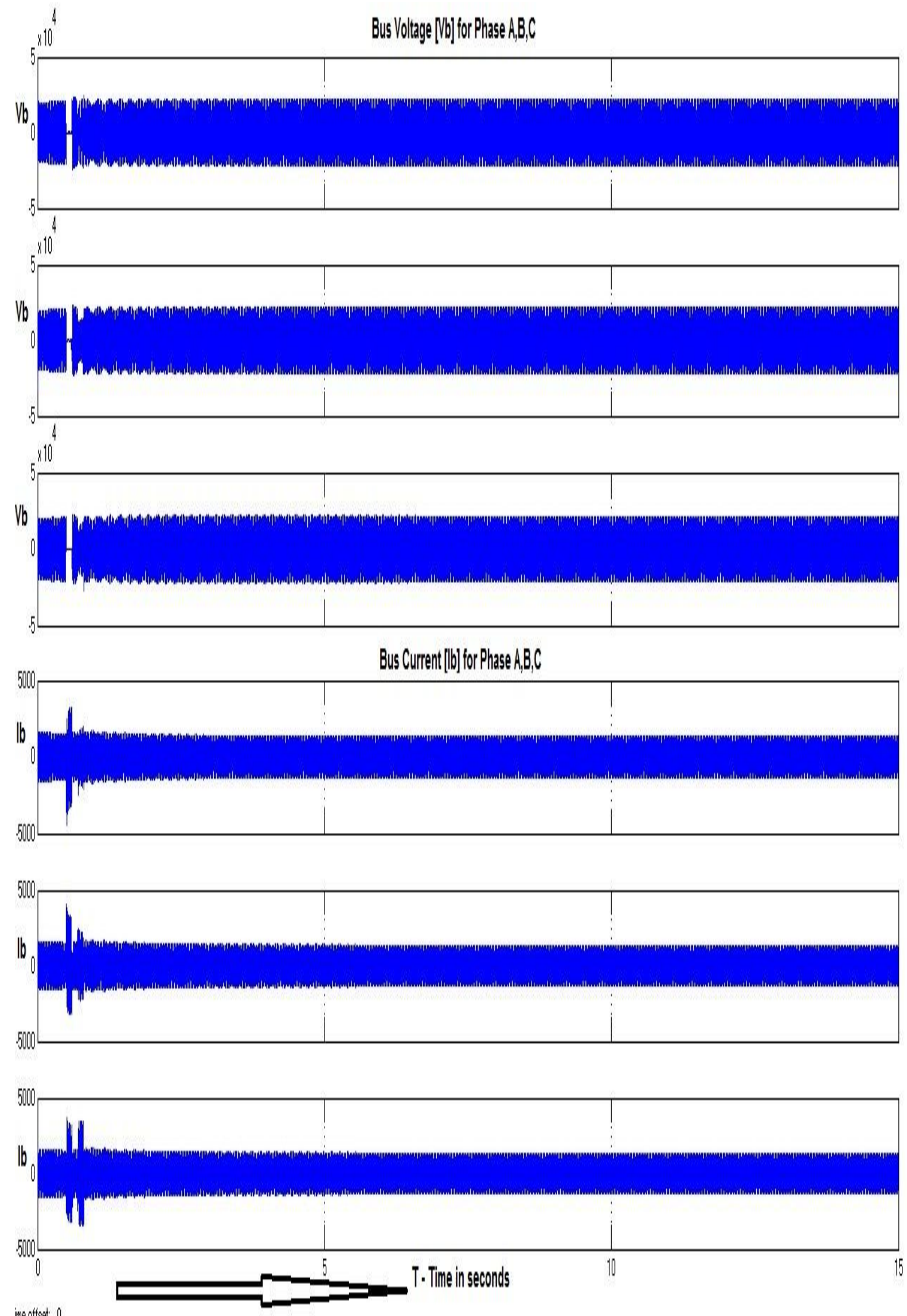

Fig.8. Represents bus voltage and current of test system with STATCOM 

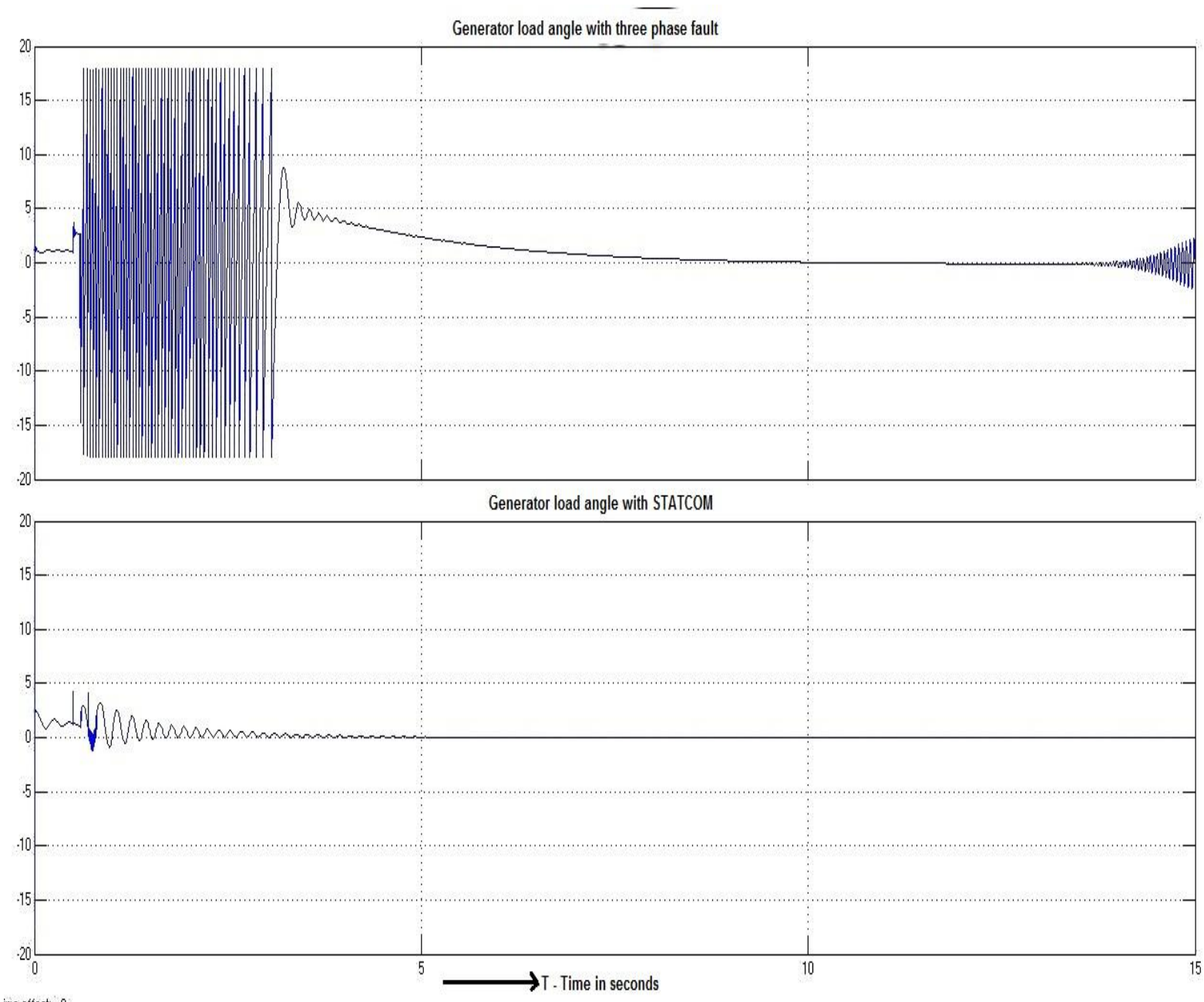

Fig-.9.Represents Generator load angle of test system with and without STATCOM

Table. 2 Test system settling time comparisons

\begin{tabular}{|l|l|l|l|}
\hline \multirow{2}{*}{$\begin{array}{l}\text { S.N } \\
\text { o }\end{array}$} & Parameters & $\begin{array}{l}\text { Settling Time } \\
\text { WACTS } \\
\text { FAthout } \\
\text { devices }\end{array}$ & $\begin{array}{l}\text { Static } \\
\text { compensator }\end{array}$ \\
\hline 1. & $\begin{array}{l}\text { Generator } \\
\text { voltage }\end{array}$ & 4.3 Seconds & 1.9 Seconds \\
\hline 2. & Bus voltage & 5.3 Seconds & 0.4 Seconds \\
\hline 3. & $\begin{array}{l}\text { Generator } \\
\text { current }\end{array}$ & 4.3 Seconds & 3.3 Seconds \\
\hline 4. & Bus current & 3.3 Seconds & 0.4 Seconds \\
\hline 5. & $\begin{array}{l}\text { Generator load } \\
\text { angle }\end{array}$ & 7.3 Seconds & 4.3 Seconds \\
\hline
\end{tabular}

From Figure 5, 6, 7 and 8 we can observe that the generator voltage and current settling time is highly reduced from 4.3 seconds to 1.9 seconds and from 4.3 seconds to 3.3 seconds respectively. Likewise the Bus voltage and current settling time is highly reduced from 5.3 seconds to 0.4 seconds and from 3.3 seconds to 0.4 seconds respectively. So the power system stability is achieved moderately better with static synchronous compensator under three phase fault in the test system.

\section{CONCLUSIONS}

In this research paper the test system is designed with three phase faults using static compensator controller. By using the static synchronous compensator in the test system the bus voltage are controlled and voltage fluctuation is reduced. Generator voltage is stabilized at 1.9 seconds. Likewise the generator current is stabilized at 3.3 seconds. But without FACTS device generator voltage and generator current reaches stabilization at 4.3 and 4.3 seconds respectively. From the table. 2 we infer that the test system with STATCOM is much better in stabilization of generator load angle, Infinite Bus voltage and current than without FACTS device.

\section{REFERENCES}

[1]. C.L.Wadhwa, "Electrical Power System", pp 306, New Age International, 2006.

[2]. Hadi Saadat, "Power system analysis" TATA McGrawHill edition, 2002.

[3]. Chintu Rza Makkar, Lillie Dewan, "Transient stability enhancement using robust FACTS controller-a brief tour, "Canadian Journal on Electrical \& Electronics Engineering Volume 1, No.7, December 2010. 
[4]. Amit Garg, Sanjay Kumar Agarwal, "Voltage Control and Dynamic Performance of Power Transmission System using STATCOM and its comparision with SVC", International Journal of Advances in Engineering and Technology, January 2012.

[5]. R.Mohan Mathur, Rajiv K.Varma, "Thyristor Based FACTS Controllers for Electrical Transmission Systems,"IEEE press series on Power Engineering, John Wiley \& Sons LTD, 2002.

[6]. Zhiping Yang, Chen Shen, Mariesa L Crow, Lingli, "An Improved STATCOM Model for Power Flow Analysis", University of Missouri, 2000.

[7] .Alper Cetin, "Design and Implementation of VSC based STATCOM for Reactive Power Compensation and Harmonic Filtering”, Middle East Technical University, 2007.

\section{BIOGRAPHIE}

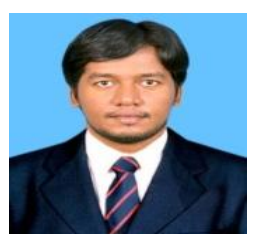

Mr.J.Vikramarajan received his Master degree in Power Electronics and Drives and Bachelor degree in Electrical and Electronics Engineering from VIT University, India. His research interests are power electronic applications, power quality, power electronic converters and power electronic controllers for renewable energy systems. 